BMJ Open

Diabetes

Research

\& Care

\title{
Key factors for overcoming psychological insulin resistance: an examination of patient perspectives through content analysis
}

Heather Stuckey, ${ }^{1}$ Lawrence Fisher, ${ }^{2}$ William H Polonsky, ${ }^{3}$ Danielle Hessler, ${ }^{2}$ Frank J Snoek, ${ }^{4}$ Tricia S Tang, ${ }^{5}$ Norbert Hermanns, ${ }^{6}$ Xavier Mundet-Tuduri, ${ }^{7}$ Maria Elizabeth Rossi da Silva, ${ }^{8}$ Jackie Sturt, ${ }^{9}$ Kentaro Okazaki (D) , ${ }^{10}$ Dachuang Cao, ${ }^{11}$ Irene Hadjiyianni, ${ }^{12}$ Jasmina I Ivanova, ${ }^{13}$ Urvi Desai (D),${ }^{13}$ Magaly Perez-Nieves ${ }^{11}$

To cite: Stuckey H, Fisher L, Polonsky WH, et al. Key factors for overcoming psychological insulin resistance: an examination of patient perspectives through content analysis. BMJ Open Diab Res Care 2019;7:e000723. doi:10.1136/ bmjdrc-2019-000723

Received 17 July 2019 Revised 17 September 2019 Accepted 1 October 2019
Check for updates

(C) Author(s) (or their employer(s)) 2019. Re-use permitted under CC BY-NC. No commercial re-use. See rights and permissions. Published by BMJ.

For numbered affiliations see end of article.

Correspondence to Dr Heather Stuckey; hstuckey@pennstatehealth. psu.edu

\section{ABSTRACT}

Objective To understand participant perceptions about insulin and identify key behaviors of healthcare professionals (HCPs) that motivated initially reluctant adults from seven countries $(n=40)$ who had type 2 diabetes (T2D) to start insulin treatment.

Research design and methods Telephone interviews were conducted with a subset of participants from an international investigation of adults with $\mathrm{T} 2 \mathrm{D}$ who were reluctant to start insulin (EMOTION). Questions related to: (a) participants' thoughts about insulin before and after initiation; (b) reasons behind responses on the survey that were either 'not helpful at all' or 'helped a lot'; (c) actions their HCP may have taken to help start insulin treatment; and (d) advice they would give to others in a similar situation of starting insulin. Responses were coded by two independent reviewers (kappa 0.992).

Results Starting insulin treatment was perceived as a negative experience that would be painful and would lead down a 'slippery slope' to complications. HCPs engaged in four primary behaviors that helped with insulin acceptance: (1) showed the insulin pen/needle and demonstrated the injection process; (2) explained how insulin could help with diabetes control and reduce risk of complications; (3) used collaborative communication style; and (4) offered support and willingness to answer questions so that participants would not be 'on their own'. Following initiation, most participants noted that insulin was not 'as bad as they thought' and recommended insulin to other adults with T2D. Conclusions Based on these themes, two actionable strategies are suggested for HCPs to help people with psychological insulin resistance: (1) demonstrate the injection process and discuss negative perceptions of insulin as well as potential benefits; (2) offer autonomy in a person-centred collaborative approach, but provide support and accessibility to address concerns. These findings help HCPs to better understand ways in which they can engage reluctant people with T2D with specific strategies.

\section{BACKGROUND}

Treatments for type 2 diabetes (T2D) include oral antihyperglycemic (OHA) medications,

\section{Significance of this study}

What is already known about this subject?

- Actions of healthcare providers have a meaningful impact on helping adults with type 2 diabetes overcome psychological insulin resistance and initiate insulin treatment.

What are the new findings?

- This study illustrates-from a patient's perspective-how healthcare providers can help alleviate reluctance to insulin initiation-by demonstrating the insulin pen/needle as well as the actual injection process, explaining the benefits of insulin, using a collaborative process of insulin initiation, and being available for support.

How might these results change the focus of research or clinical practice?

- These findings help healthcare providers to better understand ways in which they can engage reluctant people with type 2 diabetes with specific strategies.

non-insulin injectables, and insulin, in addition to lifestyle changes comprising healthy eating, exercise, and weight control. ${ }^{12}$ Because T2D is a progressive disease, over time, the effectiveness of oral medications and noninsulin injectables is no longer sufficient to provide glycemic control and hence insulin needs to be initiated. ${ }^{3}$ Despite the demonstrated efficacy of insulin in achieving adequate glycemic control and lowering the risks of long-term complications associated with T2D, ${ }^{12-6}$ as many as $30 \%$ of people with T2D are reluctant to initiate insulin for a significant period of time (up to 2 years) after an initial recommendation to do so has been made by their healthcare provider (HCP). Numerous studies have examined this 
phenomenon, termed 'psychological insulin resistance' $(\mathrm{PIR})^{8-15}$ and have documented that initiation of insulin therapy is often delayed due to a variety of physicianrelated factors (eg, lack of time, lack of knowledge about patients' concerns about insulin, clinical inertia) ${ }^{11-13}$ as well as patient-related factors (eg, anticipated weight gain, fear of injections, feelings of personal failure) ${ }^{14-16}$

Emerging research has suggested that HCP actionsparticularly those suggesting a collaborative approach tailored to the individual-have a meaningful impact on helping adults with T2D overcome PIR and initiate treatment. ${ }^{17-19}$ For example, in the multinational AccEpting Insulin TreatMent for Reluctant PeOple with Type 2 DIabetes Mellitus-A GlObal Study to IdeNtify Effective Strategies (EMOTION) survey-the source of information for the present study-we found that HCPs who are able to take the time to address injection concerns by showing and/or demonstrating the actual injection process, explaining the benefits of insulin, and adopting a collaborative, communication style are most likely to help participants overcome PIR. ${ }^{19}$ The importance of HCP interventions on compliance with insulin treatment has also been evaluated previously. For example, a recent multinational study among people with T2D using insulin found that people whose physicians took time to communicate treatment goals experienced greater adherence to insulin treatment. ${ }^{20}$ Similarly, the quantitative analysis from the EMOTION survey found that participants whose HCPs took the time to explain the benefits of insulin and dispel any myths around insulin were less likely to discontinue insulin for 7 +days after initiation. ${ }^{19}$

The present study builds on this previous quantitative research on how actions of HCPs can facilitate acceptance of insulin among people with PIR, but more importantly explores the personal experiences of adults with T2D during the process of transitioning to insulin treatment. A better understanding of peoples' perspective through key real life examples may help HCPs to successfully facilitate the difficult process of insulin initiation among adults with T2D. Specifically, this study provides a deeper understanding about perceptions about insulin before and after initiation as well as important patient-reported behaviors of HCPs that helped initially reluctant patients to start insulin. Information was gathered from exploratory interviews conducted with a subset of participants from the aforementioned EMOTION study. Based on the study findings, actionable strategies are suggested that the HCPs can use to help patients through the insulin initiation process.

\section{METHODS}

\section{Study design and sample}

Telephone interviews were conducted with a subset of 40 people who completed a quantitative survey administered as part of the EMOTION study, an international investigation focused on adults with T2D who initially experienced significant PIR prior to the initiation of regular insulin use, and agreed to participate in the follow-up interviews. The details of the study have been described elsewhere ${ }^{19}$ Briefly, the study included adults with T2D who indicated an initial reluctance to beginning basal insulin treatment, but then eventually agreed to do so (within 3 years prior to survey completion). Adults with prior insulin use or a diagnosis of type 1 diabetes were excluded. Participants were recruited from seven countries (Brazil, Canada, Germany, Japan, Spain, UK, and USA) through consumer panels, a diabetes registry, diabetes website announcements, and physician referrals.

All participants of the EMOTION study completed a 30 min online survey between January and August 2017 that, among other patient-related attributes, captured information about HCP statements and actions regarding insulin initiation that may have occurred during medical visits using a battery of 38 items included in the 'PIR Action Survey' (PAS). Each PAS item was rated on a 5-point Likert scale: 1 (did not occur) to 5 (did occur, and helped a lot). On survey completion, a convenience sample approach was used to identify participants for the present study based on the subset of the survey participants who agreed to be contacted for the follow-up interview via phone. Participants were sent an informed consent form in their native language prior to the interviews and only participants who provided consent proceeded with the interviews. The interviews were conducted in the local language. Country representatives received training from the lead qualitative investigator (Dr. Stuckey) for consistency of interview method across countries. All interviews were recorded and transcripts were translated in English for coding purposes; participant identifying information (eg, names) was removed from the transcripts.

\section{Study procedures}

Telephone interviews were typically $45-60 \mathrm{~min}$ long, during which participants were asked questions that pertained to four primary areas of exploration: (a) participants' thoughts and perceptions about insulin before and after initiation and any related factors (eg, through observation of other family members using insulin); (b) reasons behind participants' responses to the individual PIR Action Survey questions (eg, responses that were either answered on a particular end of the spectrum, as in 'not helpful' or 'helped a lot'); (c) other actions their HCP may have taken that convinced them to start insulin treatment; and (d) what advice, if any, they would give to other people with T2D who may face a similar PIR.

\section{Analysis}

Because there is little research on the experience of insulin initiation in T2D from a patient's perspective, we selected a modified grounded theory approach to analyze the qualitative data. ${ }^{2122}$ In the first phase of coding (emergent coding), we marked conceptual labels on preliminary groupings of similar phenomena. In the second phase (axial coding), the primary investigators returned to the data to revise groupings and strengthen conceptual links (themes). As a 


\begin{tabular}{|c|c|}
\hline Characteristic & Total $n=40$ \\
\hline \multicolumn{2}{|l|}{ Country, n (\%) } \\
\hline USA & $7(17.5)$ \\
\hline Canada & 9 (22.5) \\
\hline UK & $9(22.5)$ \\
\hline Germany & $4(10.0)$ \\
\hline Spain & $3(7.5)$ \\
\hline Brazil & $2(5.0)$ \\
\hline Japan & $6(15.0)$ \\
\hline Age (years), mean (SD) & $58.4(9.9)$ \\
\hline Male, n (\%) & $22(55.0)$ \\
\hline Education (years), mean (SD) & $14.3(2.5)$ \\
\hline \multicolumn{2}{|l|}{$\begin{array}{l}\text { Employment status at survey } \\
\text { completion, } \mathrm{n}(\%)\end{array}$} \\
\hline Working full-time & $13(32.5)$ \\
\hline Working part-time & $5(12.5)$ \\
\hline On sick/disability leave from work & $3(7.5)$ \\
\hline Not employed & $4(10.0)$ \\
\hline Retired & $15(37.5)$ \\
\hline $\begin{array}{l}\text { Years since first diabetes diagnosis to } \\
\text { basal insulin initiation, mean (SD) }\end{array}$ & $11.2(7.7)$ \\
\hline $\begin{array}{l}\text { HbA1c (\%) before insulin initiation, } \\
\text { mean }(S D)^{*}\end{array}$ & $9.9(2.9)$ \\
\hline $\begin{array}{l}\mathrm{HbA} 1 \mathrm{c}(\mathrm{mmol} / \mathrm{mol}) \text { before insulin } \\
\text { initiation, mean }(\mathrm{SD})^{*}\end{array}$ & $84.7(31.2)$ \\
\hline $\mathrm{HbA1c}(\%)$ current, mean (SD)* & $8.3(2.7)$ \\
\hline $\mathrm{HbA} 1 \mathrm{c}(\mathrm{mol} / \mathrm{mol})$ current, mean (SD)* & $67.7(31.0)$ \\
\hline \multicolumn{2}{|l|}{$\begin{array}{l}\text { BMI before insulin initiation }\left(\mathrm{kg} / \mathrm{m}^{2}\right) / \\
\text { Current BMI }\end{array}$} \\
\hline Mean (SD) & $31.7 / 31.8(7.8 / 7.0)$ \\
\hline$<18.5, \mathrm{n}(\%)$ & $1 / 0(2.5 \% / 0.0 \%)$ \\
\hline 18.5-24.9, n (\%) & $5 / 4(12.5 \% / 10.0 \%)$ \\
\hline 25.0-29.9, n (\%) & $13 / 16(32.5 \% / 40.0 \%)$ \\
\hline$\geq 30.0, \mathrm{n}(\%)$ & $21 / 20(52.5 \% / 50.0 \%)$ \\
\hline
\end{tabular}

*Mean $\mathrm{HbA1c}$ was calculated among the patients with a selfreported known test result $(\mathrm{n}=23$ before insulin initiation and $\mathrm{n}=29$ for most recent result within a year before survey).

BMI, body mass index; HbA1c, Hemoglobin A1c; SD, standard deviation.

part of the analysis, the study team developed the initial codebook for emergent coding, adjudicated by two independent researchers (kappa $=0.992$ ) using Nvivo 10 PRO software. This analysis sought to identify commonalities that existed within the entire sample rather than investigating differences among countries.

\section{RESULTS}

Demographics and clinical characteristics of the 40 respondents interviewed are described in table 1 . Mean age (SD) was 58.4 (9.9) years, with a relatively even distribution of males $(55 \%)$ and females $(45 \%)$. Participants had a mean (SD) of 11.2 (7.7) years since diagnosis of diabetes to first basal insulin initiation. Mean HbAlc (HemoglobinA1c) (SD) was reduced from time of insulin initiation $(9.9 \%(2.9 \%)$ or $84.7 \mathrm{mmol} / \mathrm{mol}(31.2 \mathrm{mmol} /$ $\mathrm{mol})$ ) to current self-reported levels $(8.3 \%(2.7 \%)$ or $67.7 \mathrm{mmol} / \mathrm{mol}(30.0 \mathrm{mmol} / \mathrm{mol}))$.

Table 2 describes the codes that were identified from reviewing the interview transcripts as responses to the key research questions. The codes were organized in chronological order, including (a) perceptions about insulin before initiation that may have contributed to PIR; (b) HCP actions that were helpful (or not helpful) in insulin initiation; and (c) thoughts about insulin now, after initiation. The range of responses, particularly related to the HCP actions, were further categorized to identify unique themes.

\section{Perceptions about insulin that Contributed to PIR}

Not surprisingly, the key theme emerging from the interviews regarding perceptions about insulin before initiation was that participants had negative perceptions of going on insulin, including it would hurt, or would require more time and energy from their daily routines. To the participants, going on insulin meant they had failed, and that they were not able to manage diabetes without injections. Even when they made adjustments in their diet and tried to improve diabetes management, they felt like they were not able to get their blood sugar under control to avoid insulin. Going on insulin also meant that they were at an end point, a 'last straw', and that their condition was getting more severe or deteriorating. A main contributor to this perception was the participants' observation of the experiences of their family and friends who used insulin. For example, one participant noted that their neighbor used insulin and died, which led them to believe that insulin was 'something meant only to delay the inevitable'. Another noted that they had 'grandmothers that were on insulin. Both of them were blind when they died.'

\section{HCP actions that helped overcome PIR}

A wide range of responses were elicited regarding the behaviors of the HCP that helped initially reluctant adults with T2D to overcome their hesitancy. Participant responses broadly conformed to four themes, including: (1) HCP showed the insulin pen/needle and demonstrated the injection process; (2) HCP explained how insulin could help with diabetes control and reduce the risk of complications; (3) HCPs used a collaborative communication style; and (4) HCPs were supportive and accessible to answer questions so the person with T2D would not be on their own. Each is illustrated below.

\section{Theme 1: HCPs showed the insulin pen/needle and demonstrated} the injection process

Participants reported that the injection itself was often the biggest obstacle, and that injecting oneself was 
Table 2 Codebook used in qualitative analysis with codes associated with the research question $(n=40)$

\begin{tabular}{|c|c|c|c|}
\hline Primary code & Secondary code & \# sources & \# quotes \\
\hline \multicolumn{4}{|c|}{ Negative thoughts PRIOR about going on insulin } \\
\hline & It would hurt OR don't like needles & 21 & 50 \\
\hline & Would take time and energy & 19 & 32 \\
\hline & Diabetes is stigmatized or judged as bad by others & 6 & 8 \\
\hline & Weight gain & 4 & 5 \\
\hline & Would affect family negatively & 4 & 7 \\
\hline & Would cause me to lose my job or status in society & 3 & 5 \\
\hline & Was hesitant in general (no specific reason stated) & 13 & 15 \\
\hline \multicolumn{4}{|c|}{ First reaction to going on insulin } \\
\hline & Fearful & 28 & 53 \\
\hline & Thought my health had gotten worse & 21 & 27 \\
\hline & Thought I had failed & 18 & 28 \\
\hline & Surprised & 14 & 17 \\
\hline & Sad & 11 & 15 \\
\hline & Not surprised & 11 & 13 \\
\hline \multicolumn{4}{|c|}{ Friends or family member actions } \\
\hline & Knew other people on insulin & 28 & 54 \\
\hline & Friends or family provided support for insulin & 14 & 29 \\
\hline \multicolumn{4}{|c|}{ HCP actions (positive) } \\
\hline & Said insulin would help with diabetes control & 28 & 56 \\
\hline & Established trust with me & 26 & 65 \\
\hline & HCP available for support or questions & 22 & 41 \\
\hline & Gave me injection in the office & 21 & 36 \\
\hline & HCP explained giving insulin was easy & 19 & 32 \\
\hline & Referred me to a specialist, endocrinologist, etc & 17 & 25 \\
\hline & $\begin{array}{l}\text { Told me about the side effects of insulin (ie, } \\
\text { hypoglycemia) }\end{array}$ & 15 & 23 \\
\hline & Honest about what could happen if I didn't comply & 13 & 26 \\
\hline & Gave reading material about insulin & 12 & 18 \\
\hline & Shared decision making for going on insulin & 9 & 16 \\
\hline & Referred me to a diabetes education, nutrition class & 7 & 9 \\
\hline & HCP positives in general (not listed above) & 11 & 14 \\
\hline
\end{tabular}

Negative thoughts NOW about going on insulin

\begin{tabular}{lrc} 
Burden overall & 21 & 49 \\
Causes weight gain for me & 12 & 14 \\
\hline More worry from friends and family & 11 & 14 \\
Causes hypoglycemia for me & 6 & 7 \\
Makes me feel different (ie, in society) & 4 & 4
\end{tabular}

Positive thoughts NOW about going on insulin

$\begin{array}{lrr}\text { Helps me control my diabetes } & 31 & 57 \\ \text { Not as bad as I thought } & 28 & 72 \\ \text { Lifestyle hasn't had to change much } & 16 & 25 \\ \text { Helps me feel better } & 11 & 13 \\ \text { Insulin is a natural substance for the body } & 8 & 10 \\ \text { Easy to take the right amount of insulin } & 7 & 8\end{array}$


Table 2 Continued

\begin{tabular}{llrr}
\hline Primary code & Secondary code & \# sources & \# quotes \\
\hline & Can look up information on my own about insulin & 5 & 6 \\
& General (other) & 17 & 27 \\
\hline Advice or helpful information to others going on insulin & 24 & 41 \\
Finances and cost & & 30 & 41 \\
& Financial successes of insulin & 8 & 7 \\
\hline
\end{tabular}

$\mathrm{HCP}$, healthcare professional.

perceived as 'horrible' and 'terrible'. To alleviate this fear of needles, participants described how their HCP explained that the needle was small and the pain, minor. Several people reported that their HCP injected the needle (from an insulin syringe or an insulin pen), in the office and they did not feel any pain at all, which encouraged participants to begin insulin treatment.

The doctor brought a needle like the one that would be used. I said 'Wow, it is quite small and very thin'. So as soon as I saw the needle, I already accepted it more. I then did a test and I injected myself on the stomach. And when I did it, I said 'Wow, I can't feel anything'.

I think that my doctor showing me in the office was a big help ... if I had to come home and do it without him showing me, I would have been scared.

\section{Theme 2: HCPs explained how insulin could help with diabetes control and reduce the risk of complications}

An important HCP action to overcome insulin resistance was telling their patients how insulin could help with diabetes control by lowering their HbA1c and reducing the chances of developing complications in the future. Some HCPs had expressed concern about the HbAlc being too high and told participants that they needed the insulin to lower it. Some HCPs also mentioned other benefits of going on insulin, such as the reduction of the 'burden on the body', which would help people with T2D feel better overall.

Basically what he said is, the only thing that's going to allow you to up your diet and the number of carbohydrates is you are going to have to lower your blood sugar and the only way you can do it is with insulin.

They mentioned the benefits. That it is good for my [overall] health, because of the high levels ... and the use of insulin does not cause any complications ... it was a sensible decision that I did not reject it ... it also helped disperse my worries and fears.

$\mathrm{He}$ told me that taking insulin would be a good opportunity to give the liver and kidneys a rest [from the other medication].

\section{Theme 3: HCPs used a collaborative communication style}

Several participants described how, even though their HCP recommended that they go on insulin, their HCPs used a collaborative approach to decision-making. Their HCP told them that it was up to them; where they were not pushed into taking the medication, but that it was an option and their choice, all of which helped the participants feel like they had a sense of autonomy in the decision to start insulin.

The doctor could quite easily have said 'you need to take insulin now, here it is,' but it wasn't like that, it was I felt as though I was being consulted in the choice...I was led to the choice that this was the best way forward ... It wasn't a case of 'you're taking that', it was to make sure I was comfortable with it before I started. It wasn't rushed.

He [the HCP] wasn't forceful and he left it with my willingness. It was like we both were thinking the same thing at the same time...

Additionally, HCPs were reported to be willing to engage in a dialogue with the participants, which helped them make an informed decision rather than just following the direction of the HCP. Participants were also grateful that they were not rushed into making a decision, and they reported having several discussions with their HCPs around their treatment options before a decision was made. One participant noted how his HCP would explain how the pancreas worked and how the insulin-producing cells were not working well enough. The insulin was giving a 'wee gentle help' and the image created for one participant was that of a 'little old female insulin cell with a crutch'. This description helped the participants feel confident in the HCPs' recommendations. The quotes below further exemplify how the need to go on insulin was discussed collaboratively, and then a mutual decision reached:

He said 'you've done really well on the tablets, you've really worked at it, but it's getting to the stage where it's nothing you're doing, it's just how the diabetes is going and maybe you need to have this to bring it back to where you can manage it'. So I actually said to them 'I think you're right, I'm going to have to go down the insulin route'.

After all, if such an understanding doctor suggested insulin, you would accept it but on the other hand, if a doctor were demanding me to try harder, do this, do that... That would make me think "Never!" 
Theme 4: HCPs were supportive and accessible to answer questions so people with T2D would not be on their own

People with T2D said that it was good to know that HCPs would be there at any time if there were concerns or queries during the insulin initiation process, rather than needing to wait until the next appointment. It was reassuring for participants to have a medical professional at the end of the line, ready to answer questions. The doctor's or nurse's availability showed support because it reinforced that the participants were not on their own, which helped to alleviate worry. One woman was unsure of the process of giving insulin while at home, and she called her provider who walked her through the steps several times until she was confident of the injection process. If the insulin dose was not improving blood sugar, some patients felt comfortable reaching out to their doctor and tell them they were struggling. The few minutes spent listening to patient concerns and asking 'is this working for you?' was helpful in feeling supported through the insulin initiation process.

\footnotetext{
They have always been available by email or if I have needed to phone call. But I have emailed if I had any questions or concerns and we have emailed back and forth.

The doctor was going to let me come in every day and have them help me through it.
}

\section{Current participant perceptions about insulin}

After participants had been using insulin, many of them saw insulin as 'no big deal', and nearly all said that they would recommend insulin to others who needed it. They noted how taking insulin had become part of their life or an 'old hat', and the fear of the unknown had been worse than the injection itself. One said after she got over the 'initial hurdle of 'I've got to stick this in myself', she got used to it and it no longer was 'as daunting as what it used to be'. Another noted that although it may seem like a 'massive thing', after a while, 'you do adapt to it; it's not the end of the world, even though you often think it is'. One other participant offered the following advice to other adults with T2D who may be facing a similar challenge as he once did:

It's really easy to cope with it, and you will feel better and you will get your blood sugars down - you just have to be organized and make sure you take enough tests throughout the day to make a pattern of what's happening. You can correlate your blood sugar levels to what you're eating to work on an informed basis and you can go fine. And you will feel better and healthier.

\section{Additional considerations noted by the participants}

Two additional themes emerged from participant responses.

\section{Friend or family member support}

A few participants noted that receiving support from their friends and family also helped them initiate and continue insulin treatment. One respondent's sister asked them to not give up and to just 'see how it works', which also helped them overcome PIR.

\section{Financial considerations}

While some financial struggles with insulin were mentioned, generally, they were not a prominent factor in the decision to begin insulin use. While we do not know how many of these individuals had insurance or national healthcare plan coverage, many participants did note that they received free or reimbursed insulin, covered by insurance, such as this woman: 'The insulin...like I said, I never really know what it costs because I don't have to pay for that'.

\section{DISCUSSION}

Consistent with other research, this study found that adults with T2D who had PIR generally had negative perceptions about insulin. ${ }^{14-16}$ The key motivating factors to eventual insulin acceptance and use were supportive actions taken by HCPs to provide a better understanding of the injection process, the benefits about insulin, and the collaborative and supportive relationship. Although this paper was completed independently from the quantitative survey, the results are consistent with the EMOTION survey, ${ }^{19}$ as well as results reported by other studies. ${ }^{1718}{ }^{20}$ Additionally, the qualitative study helps us understand the ways in which HCPs can engage in the specifics of these behaviors. These observations also align with the most recent recommendations from the American Diabetes-Association (ADA)/European Association for the Study of Diabetes (EASD) ${ }^{2}$ for the management of hyperglycemia in T2D, underscoring the importance of a personalized, patient-centred approach.

Our study findings add to this literature by providing a greater understanding of the drivers of patients' perceptions about insulin and how it evolves over time. Of particular note is the role the HCP can play in the eventual initiation of insulin. For example, more than half of the adults had preconceived negative assumptions regarding the large size of the needle and the pain associated with taking the injection. These assumptions were subsequently dispelled when the HCP showed them the size of the needle and administered an injection in their own office. Similarly, through observations of outcomes among other people using insulin, participants thought that using insulin is associated with more complications. However, they were pleasantly surprised when they saw the drastic reductions in their blood glucose levels after starting insulin and felt better overall.

Based on these qualitative data and in line with the grounded theory approach, we outline a series of actionable HCP strategies that, as reported by participants, help with insulin initiation among adults with T2D who initially demonstrate PIR.

\section{Two actionable HCP strategies to help overcome PIR}

1. When recommending insulin therapy, HCPs should ask adults with T2D about their perceptions regarding 
insulin and the injection process, and take necessary actions to alleviate any concerns.

a. Many people with T2D generally have several false assumptions about the injection process, such as insulin needles are big and that they hurt. To alleviate such concerns, HCPs could ask questions such as, 'What do you think about taking insulin injections? What do you know about the size of the needle?' They could show the pen/size of the needle and demonstrate the injection process to build competency.

b. Many people with T2D believe that beginning insulin is a concrete indication that their diabetes is getting worse and that complications are inevitable (the 'slippery slope'). HCPs could ask questions such as, 'How do you think going on insulin would affect your health? Worse? Better?', and reassure them that insulin will most likely improve blood glucose and reduce the risk of complications.

2. Support autonomy by using a collaborative communication style to engage people with T2D in the decisionmaking process, since ultimately it is their decision, and be available to address concerns as they transition to insulin.

Once insulin therapy is initiated, continue discussions about their experience on insulin and share these with other people with PIR to help them overcome the reluctance.

The results of this study underscore the importance of understanding and addressing patient perceptions about disease progression as well as insulin use early in the treatment process, and of providing a supportive environment to help facilitate insulin initiation. However, this study should be viewed within the context of certain limitations. Due to the small sample size, the interviewed participants may not be representative of all people with T2D who are reluctant to initiate insulin. For example, T2D is most prevalent among non-White ethnicities ${ }^{23}$; however, in this study, the majority of participants were Caucasian. Similarly, people volunteering to participate in research, and in particular those agreeing for in-depth interviews following the initial online survey, may have a higher literacy level than the overall T2D patients. Additionally, this study may be subject to limitations that are inherent to survey-based studies (ie, self-reported data for past events may be subject to recall bias). However, given that the initiation of insulin is an important milestone in diabetes management, it is likely that people can accurately recall their experience and the events that aided their successful initiation. Future interventions could test the actionable strategies to reduce PIR and improve T2D outcomes in more diverse patient populations.

\section{CONCLUSIONS}

The study illustrates-from a patient's perspective-how HCPs can help to alleviate reluctance to insulin initiation-by demonstrating the insulin pen/needle as well as the actual injection process, explaining the benefits of insulin, using a collaborative process of insulin initiation, and being available for support. Additionally, based on the study findings, two actionable strategies that the HCPs can use to help patients through the insulin initiation process are suggested: (1) discuss and alleviate negative perceptions of insulin as well as discuss the potential benefits of insulin; (2) support autonomy using a personcentred collaborative approach to treatment while also being available to address concerns.

\section{Author affiliations}

${ }^{1}$ Pennsylvania State University, Hershey, Pennsylvania, USA

2University of California San Francisco, San Francisco, California, USA

${ }^{3}$ Behavioral Diabetes Institute, University of California, San Diego, Del Mar,

California, USA

${ }^{4}$ Amsterdam University Medical Centre Vrije Universiteit, Amsterdam, The Netherlands

${ }^{5}$ University of British Columbia, Vancouver, British Columbia, Canada

${ }^{6}$ Diabet Acad Mergentheim FIDAM, Bad Mergentheim, Germany

${ }^{7}$ Universitat Autonoma de Barcelona, Bellaterra, Spain

${ }^{8}$ Hospital das Clínicas da Faculdade de Medicina da USP, Sao Paulo, Brazil

${ }^{9}$ King's College London, London, UK

${ }^{10}$ Nagoya University Graduate School of Medicine, Nagoya, Japan

${ }^{11}$ Eli Lilly and Company, Indianapolis, Indiana, USA

${ }^{12}$ Lilly Deutschland GmbH, Bad Homburg, Germany

${ }^{13}$ Analysis Group Inc Boston, Boston, Massachusetts, USA

Acknowledgements The authors thank Ariel Rokito, an employee of Analysis Group, Inc. at the time of the study for her support in conducting the data analyses.

Contributors HS contributed to study design, data collection and analysis, interpretation of results, and critical revision of the manuscript. UD contributed to data collection and analysis, interpretation of results, and drafting the manuscript. All other authors contributed to the study design and interpretation of findings, and critically revised the manuscript for important intellectual content.

Funding Research funding was provided by Eli Lilly and Company, Indianapolis USA.

Competing interests HS, DH, FJS, XM-T, and MERS have served as consultants for Eli Lilly and Company. WHP has served as a consultant for Eli Lilly, Novo Nordisk, Sanofi, Astra Zeneca, Dexcom, Intarcia, Merck and Mannkind. LF has served as a consultant for Eli Lilly and Abbott Diabetes Care. TST has served as a consultant for Eli Lilly and Omni Pod. JS has served as a consultant for Eli Lilly and Spirit Healthcare. NH reports grants and personal fees from Abbott, Berlin Chemie, Ypsomed, Lilly, Dexcom and Roche. KO has served as a consultant for Eli Lilly and Eli Lilly Japan K.K., ONO Pharmaceutical Co., Kowa Co., Sanwa Kagaku Kenkyusho Co., Mitsubishi Tanabe Pharma Corporation, ARKRAY Inc., Sanofi K.K., Abbott Japan Co., MSD K.K., Novartis Pharma K.K., Novo Nordisk, and Nippon Boehringer Ingelheim Co. DC is an employee of Eli Lilly and Company. IH and MP-N are employees and stockholders of Eli Lilly and Company. UD is an employee of Analysis Group, Inc., a company that received funding for this research from Eli Lilly and Company. JII was an employee of Analysis Group, Inc. at the time of the study.

\section{Patient consent for publication Not required.}

Ethics approval This study was performed in accordance with principles of the Declaration of Helsinki. Regulatory approval for this study was provided by the Western Institutional Review Board (Puyallup, WA), Pennsylvania State University Hershey College of Medicine IRB (Hershey, PA) as well as Nagoya University IRB, Nagoya, Japan.

Provenance and peer review Not commissioned; externally peer reviewed.

Data availability statement No data are available as the information collected during patient interviews is considered confidential, and disclosure to third parties is not permitted.

Open access This is an open access article distributed in accordance with the Creative Commons Attribution Non Commercial (CC BY-NC 4.0) license, which permits others to distribute, remix, adapt, build upon this work non-commercially, 
and license their derivative works on different terms, provided the original work is properly cited, appropriate credit is given, any changes made indicated, and the use is non-commercial. See: http://creativecommons.org/licenses/by-nc/4.0/.

ORCID iDs

Kentaro Okazaki http://orcid.org/0000-0002-8449-804X

Urvi Desai http://orcid.org/0000-0001-5196-7201

\section{REFERENCES}

1 American Diabetes Association. Standards of medical care in diabetes - 2018. Diabetes Care 2018;41:S1-159.

2 Davies MJ, D'Alessio DA, Fradkin J, et al. Management of hyperglycemia in type 2 diabetes, 2018. A consensus report by the American diabetes association (ADA) and the European association for the study of diabetes (EASD). Diabetes Care 2018;41:2669-701.

3 Fonseca VA. Defining and characterizing the progression of type 2 diabetes. Diabetes Care 2009;32 Suppl 2:S151-6.

4 Oguz A, Benroubi M, Brismar K, et al. Clinical outcomes after 24 months of insulin therapy in patients with type 2 diabetes in five countries: results from the treat study. Curr Med Res Opin 2013;29:911-20.

5 Bhattacharya R, Zhou S, Wei W, et al. A real-world study of the effect of timing of insulin initiation on outcomes in older Medicare beneficiaries with type 2 diabetes mellitus. J Am Geriatr Soc 2015;63:893-901.

6 Chen H-S, Wu T-E, Jap T-S, et al. Beneficial effects of insulin on glycemic control and beta-cell function in newly diagnosed type 2 diabetes with severe hyperglycemia after short-term intensive insulin therapy. Diabetes Care 2008;31:1927-32.

7 Hosomura N, Malmasi S, Timerman D, et al. Decline of insulin therapy and delays in insulin initiation in people with uncontrolled diabetes mellitus. Diabet Med 2017;34:1599-602.

8 Polonsky WH, Hajos TRS, Dain M-P, et al. Are patients with type 2 diabetes reluctant to start insulin therapy? An examination of the scope and underpinnings of psychological insulin resistance in a large, International population. Curr Med Res Opin 2011;27:1169-74.

9 Polonsky WH, Fisher L, Guzman S, et al. Psychological insulin resistance in patients with type 2 diabetes: the scope of the problem. Diabetes Care 2005;28:2543-5.

$10 \mathrm{Ng} \mathrm{CJ}$, Lai PSM, Lee YK, et al. Barriers and facilitators to starting insulin in patients with type 2 diabetes: a systematic review. Int $J$ Clin Pract 2015:69:1050-70.
11 Nakar S, Yitzhaki G, Rosenberg R, et al. Transition to insulin in type 2 diabetes: family physicians' misconception of patients' fears contributes to existing barriers. J Diabetes Complications 2007;21:220-6.

12 Shah BR, Hux JE, Laupacis A, et al. Clinical inertia in response to inadequate glycemic control: do specialists differ from primary care physicians? Diabetes Care 2005;28:600-6.

13 Parchman ML, Pugh JA, Romero RL, et al. Competing demands or clinical inertia: the case of elevated glycosylated hemoglobin. Ann Fam Med 2007:5:196-201.

14 Oliveria SA, Menditto LA, Ulcickas Yood M, et al. Barriers to the initiation of, and persistence with, insulin therapy. Curr Med Res Opin 2007;23:3105-12.

15 Peyrot M, Barnett AH, Meneghini LF, et al. Insulin adherence behaviours and barriers in the multinational global attitudes of patients and physicians in insulin therapy study. Diabet Med 2012;29:682-9.

16 Polonsky WH, Arsenault J, Fisher L, et al. Initiating insulin: how to help people with type 2 diabetes start and continue insulin successfully. Int J Clin Pract 2017;71:e12973.

17 Abu Hassan $\mathrm{H}$, Tohid $\mathrm{H}$, Mohd Amin R, et al. Factors influencing insulin acceptance among type 2 diabetes mellitus patients in a primary care clinic: a qualitative exploration. BMC Fam Pract 2013; $14: 164$

18 Gauthier B, Singh SR, Virani A, et al. Perspectives and experiences of health care professionals and patients regarding treatments for type 2 diabetes. Can Pharm J 2014;147:45-54.

19 Polonsky WH, Fisher L, Hessler D, et al. Identifying solutions to psychological insulin resistance: an international study. J Diabetes Complications 2019;33:307-14.

20 Linetzky B, Jiang D, Funnell MM, et al. Exploring the role of the patient-physician relationship on insulin adherence and clinical outcomes in type 2 diabetes: insights from the mosaic study. $J$ Diabetes 2017:9:596-605.

21 Bryant A, Charmaz K. The SAGE Handbook of grounded theory. Thousand Oaks, CA: SAGE, 2007.

22 Glaser BG. Doing grounded theory. Mill Valley, CA: Sociology Press, 1998.

23 American Diabetes Association. Statistics about diabetes, 2018. Available: http://www.diabetes.org/diabetes-basics/statistics/ [Accessed 2 Jul 2018].

24 Diabetes statistics in Canada, 2018. Available: http://www.diabetes. $\mathrm{ca} / \mathrm{how}$-you-can-help/advocate/why-federal-leadership-is-essential/ diabetes-statistics-in-canada [Accessed 2 Jul 2018] 